\title{
CONCEPTION AND REALISATION OF A SENSOR ELECTROMAGNETIC FORCE-DISPLACEMENT
}

\author{
Z.Ezzouine $^{1}$, A. Nakheli ${ }^{2}$, Z. Abbassi ${ }^{3}$, A. Benabdellah ${ }^{4}$ \\ ${ }^{1}$ LASMAR, Faculty of Sciences, Moulay Ismail University, Meknes, Morocco \\ ${ }^{2}$ Electrical Engineering Departments, ESTM, Moulay Ismail University, Meknes, Morocco \\ ${ }^{3}$ LASMAR, Faculty of Sciences, Moulay Ismail University, Meknes, Morocco \\ ${ }^{4}$ LASMAR, Faculty of Sciences, Moulay Ismail University, Meknes, Morocco
}

\begin{abstract}
The experimental device that we propose is an electromagnetic sensor permits the measures of force and displacement. her principle of working rests on the phenomenon of influence by magnetic induction between two flat spools, in the same way diameter and including the same number of spires, situated to a certain distance, $x$, one of the other, on a same axis passing by their centers. The sensor is constituted of two converters, the first is the spring (converter force-displacement), and the second is a magnetic circuit permitting the conversion of the displacement in tension (converter displacement - tension) via the electronic circuit of conditioning.
\end{abstract}

Keywords: Sensor electromagnetic, converter force-voltage, converter force-displacement

\section{INTRODUCTION}

In the field of physical instrumentation, there are many sensor measuring force and displacement; they are generally electrodynamics sensors Piezoelectric, or using strain gauges [1-9].

The electromagnetic sensor of force-displacement we propose is similar to the spring balance (of which one usually measures the elongation using a ruler moving on a graduated scale), to which we associated a converter distortion- voltage. The given measures are strengths that can be convert them by the displacements, knowing the characteristic of the spring, $\mathrm{k}=2 \mathrm{mg} / \mu \mathrm{m}$ and the relation $\mathrm{x}=$ $\mathrm{m} / \mathrm{k}$.

\section{DESCRIPTION OF THE SENSOR}

\section{ELECTROMAGNETIC}

The operating principle of the sensor is based on the magnetic induction created by the fixed coil, gives rise to an electromotive force at the terminals of the voice coil, that depends on the distance $\mathrm{x}$ between the coils. When asked on a mass tare spring lengthens, the cylinder moves downward, and the distance between the coils $\mathrm{x}$ decreases. This results in an increase in the voltage across the moving coil. The spring plays the role of a converter force- displacement. The conceived device is an electromagnetic force sensor, and can also be considered as a displacement sensor.

The sensor of forces that we propose consists of a spring $\mathrm{R}$, two flat coils of 30 coils each, and of $2 \mathrm{~cm}$ radius, and a flat coil is mounted on a support around a hole (transmitting coil), it is supplied by a sinusoidal signal from a Low Frequency Generator. The second coil receiving platform
$\mathrm{BM}$ is wound on an insulating cylinder of $2 \mathrm{~cm}$ radius and $5.3 \mathrm{~cm}$ height, The latter is suspended by a hook at the lower end of a spring whose upper end is fixed on a support through a hook Fig -1.

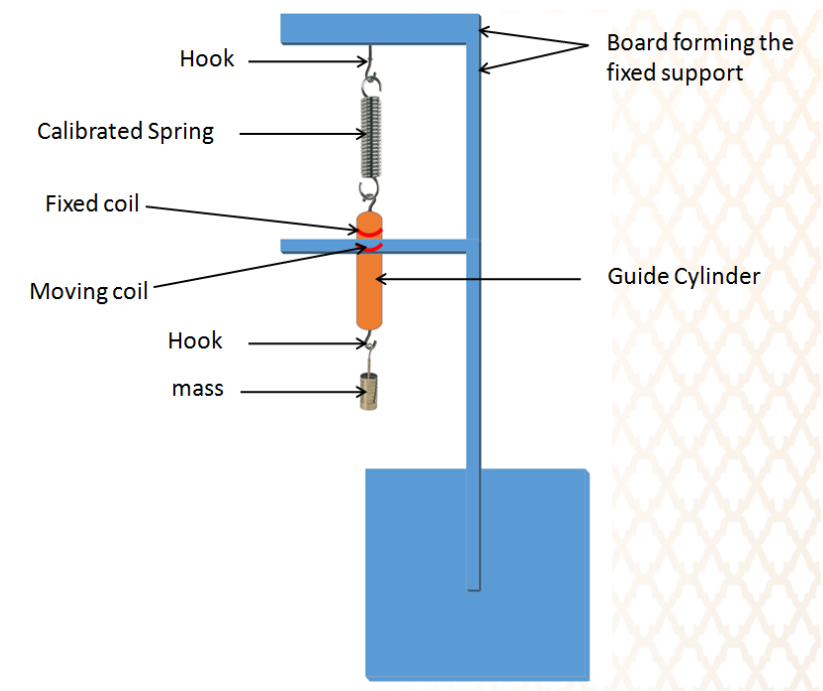

Fig -1: The sensor for electromagnetic forces

The spring assembly, cylinder and port are well aligned vertically in a manner that the cylinder passes through the hole virtually without friction. The two receiving coils and issuing are linked to the conditioning circuit through the wires of connections. A hook is fixed on the lower part of the cylinder and is used to suspend the masses. The two coils are still parallel, remote $\mathrm{X}$ one of the other, $\mathrm{X}$ being the variable distance between coils.

$$
e=-\frac{d \Phi}{d t}
$$


The fixed coil is supplied by an low frequency generator of a frequency $\mathrm{fO}=16 \mathrm{KHz}$ whose phase conditions and amplification are satisfactory, and therefore it is traversed by a sinusoidal current which creates a sinusoidal magnetic flux density along its axis, the latter creates through the moving coil a variable flow $\Phi$ and induced sinusoidal electromotive force measurable, The maximum value of this Electrometric Force induced depends on the distance $\mathrm{x}$ between the two coils, and the flux $\Phi$ is proportional to the magnetic induction $\mathrm{B}$, whose variation, as a function of $\mathrm{x}$, is given by the following relationship [9-10]:

$$
B(x)=\frac{\mu_{0} * N^{*} I * R^{2}}{2 *\left(R^{2}+X^{2}\right)^{3 / 2}}
$$

With I the current flowing through the coils, $\mathrm{R}$ their radius, $\mathrm{N}$ their number of spire, and $\mathrm{x}$ the distance between the two coils. For $\mathrm{x}=0$, the previous formula becomes simple, and thus:

$$
B(0)=\frac{\mu_{0} * N * I}{2 R}
$$

When a mass suspended on the hook on the bottom of the cylinder, the latter moves down by extending the spring, and the distance $\mathrm{x}$ between the two coils is reduced and as a result the voltage induced across the receiver moving coil increases. The induced voltage is sinusoidal and its amplitude is low, so it has been necessary to introduce circuits for amplification, rectification and filtering to make this voltage usable, the corresponding sensor output signal conditioning circuit is as follows [11]:

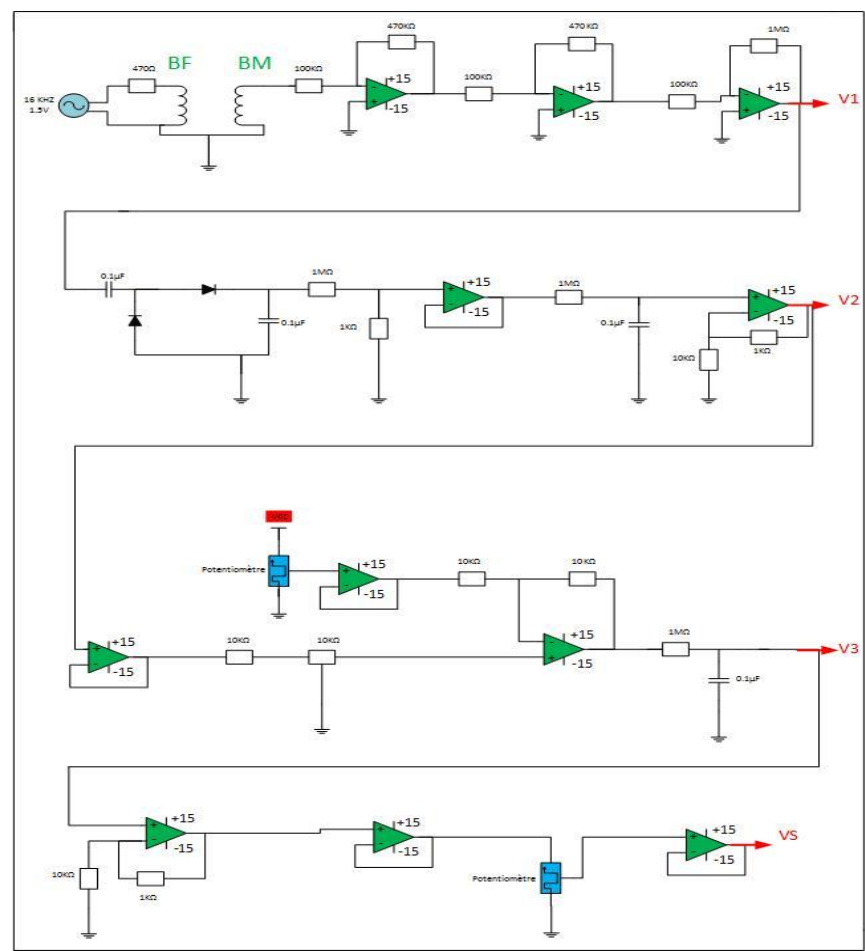

Fig-2: Conditioning circuit
The conditioning circuitry is powered by a stabilized supply symmetrical \pm 15 (Fig -3).

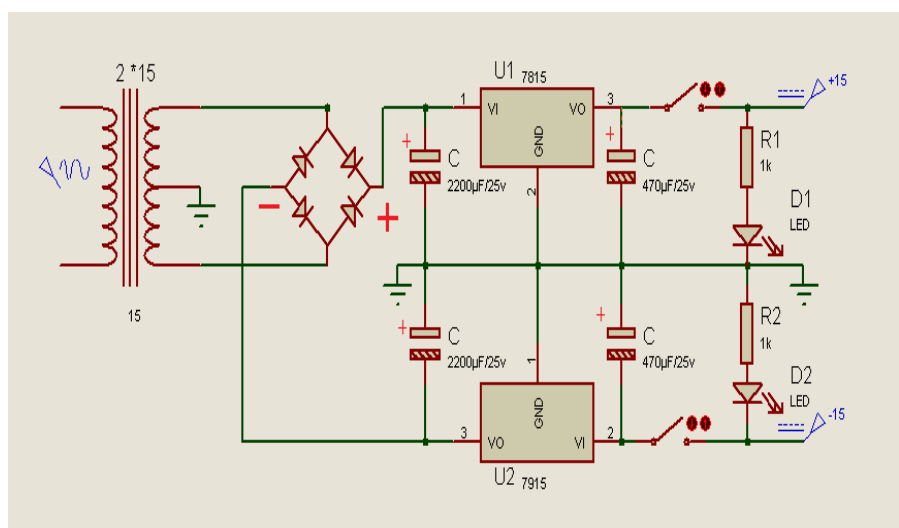

Fig -3: supply to the electronic circuit card conditioning

\section{PERFORMANCE OF THE}

\section{ELECTROMAGNETIC SENSOR}

\subsection{Sensor Drift}

When we turn the sensor on, the output voltage decreases exponentially and after 30 to 60 minutes of operation, this voltage stabilizes at a characteristic constant of the experimental device.

\subsection{Sensitivity}

The sensitivity of the sensor depends on the spring constant of the spring used and conditioning circuit (particularly the gain of the amplifier stages), we achieved a sensitivity of $\mathrm{S}=200 \mathrm{mg} / \mathrm{mV}$, at the beginning (before suspending masses). However, the electromagnetic unit consisting of transmitter and receiver coil may be modified to increase the sensor sensitivity. In general, inductive sensors were first used for historical reasons, but are still interesting because of their accuracy and robustness. In addition, the coils are cheap and easy to produce industrially, at least within reasonable dimensions. The induction of a coil is directly related to its number of turns, its diameter and thus its size; the small coils generally have a lower sensitivity. However, advanced techniques now allow the production of coils of small size with high sensitivity, with complex shapes or a larger number of turns. The frequency domain for an inductive sensor depends strongly of its impedance.

\subsection{Measuring Range}

From $0 \mathrm{~g}$ to $10 \mathrm{~g}$, it's related to the mechanical properties of the spring. The sensor is designed to work in a range of 0 to $10 \mathrm{~g}$.

\subsection{Accuracy}

The sensor accuracy depends on the specific elements of the experimental device (coils, cylinder, friction, distance between coils, spring, and the signal conditioning circuit), and on the quality of the measuring instrument used. In our case we used a digital multimeter whose accuracy is 0.1 $\mathrm{mV}$. The voltages delivered by the sensor are measured with 
an error of $0.05 \mathrm{mV}$, and the accuracy of the measured masses is estimated to $\Delta \mathrm{m}=10 \mathrm{mg}$ at the origin. So we can say that all measure masses between 0 and $10 \mathrm{~g}, \Delta \mathrm{m}$ is equal or less than $\Delta \mathrm{m}=10 \mathrm{mg}$. This is related to the sensor sensitivity which is variable and depends on the distance between coils, this sensitivity changes from $200 \mathrm{mg} / \mathrm{mV}$ to $80 \mathrm{~g} / \mathrm{mV}$, so the precision of the sensor of force and displacement :

$$
8 \mathrm{mg} \leq \Delta \mathrm{m} \leq 20 \mathrm{~g} ; 4 \mu \mathrm{m} \leq \Delta \mathrm{x} \leq 10 \mu \mathrm{m} .
$$

\subsection{Hysteresis}

We have made measurement on the sensor by hooking increasingly masses of $0 \mathrm{~g}$ to $10 \mathrm{~g}$ per $1 \mathrm{~g}$ in steps of $1 \mathrm{~g}$, and then we note the output voltage values by removing masses in steps of $1 \mathrm{~g}$. The results are perfectly reversible and there was no hysteresis cycle due to the mechanical properties of the spring which acts as a force-displacement converter. We were limited to a maximum weight of $10 \mathrm{~g}$, and beyond, there is a small deformation appearing. The choice of a good spring (perfectly elastic) is important. The spring constant of the spring used is $\mathrm{k}=2 \mathrm{mg} / \mu \mathrm{m}$.

\section{CALIBRATION OF THE SENSOR OF FORCE}

The characteristic curve of the sensor shown in Fig-3 is obtained by hooking high-precision masses from $0 \mathrm{~g}$ to $10 \mathrm{~g}$ in steps of $1 \mathrm{~g}$ (Table -1), and we note the voltage values corresponding to each mass with a voltmeter of precision $0.1 \mathrm{mV}$. The curve response is not linear; it is rather parabolic in relation with the sensor sensitivity as a function of the distance between coils.

Table -1: Sensor Electromagnetic of Force Calibration

\begin{tabular}{|l|l|l|l|l|l|l|}
\hline $\mathbf{m}(\mathbf{g})$ & 0 & 1 & 2 & 3 & 4 & 5 \\
\hline $\mathbf{V}(\mathbf{m v})$ & 9.85 & 15.25 & 21.05 & 27.25 & 34.05 & 41.25 \\
\hline
\end{tabular}

\begin{tabular}{|l|l|l|l|l|l|}
\hline $\mathbf{m}(\mathbf{g})$ & 6 & 7 & 8 & 9 & 10 \\
\hline $\mathbf{V ( m v )}$ & 49.15 & 57.65 & 67.15 & 77.75 & 88.75 \\
\hline
\end{tabular}

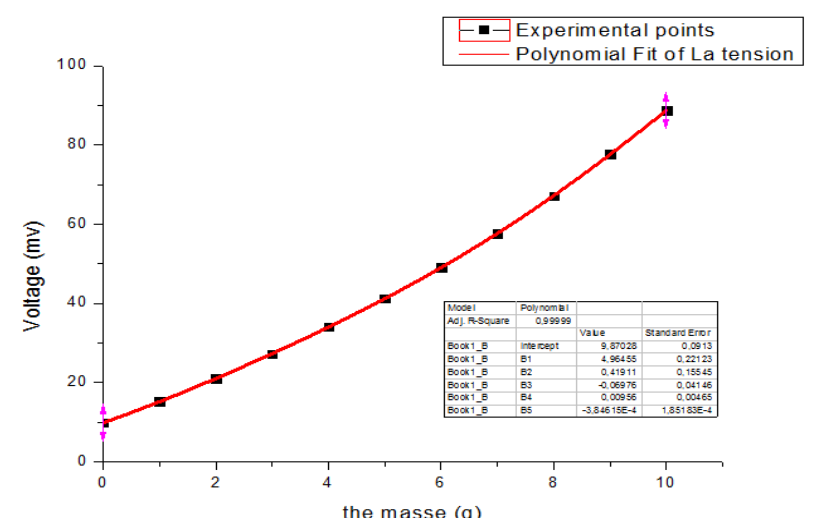

Chart -1: Sensor response from $0 \mathrm{~g}$ to $10 \mathrm{~g}: \mathrm{m}=\mathrm{f}(\mathrm{V})$

We used a polynomial fit of order 5 which is characterized by a standard deviation commensurate with the experimental sensor accuracy. The polynomial fit of the mass as a function of the voltage $(m=f(V))$ shown below will be most useful for determining the mass of any unknown by knowing its corresponding voltage delivered by the sensor. The corresponding polynomial adjustment is given by:

$$
m=\sum_{i=0}^{5} a v_{i}^{i}
$$

The polynomial adjustment of the mass as a function of the voltage corresponding to the experimental accuracy of our sensor is as follows:

$$
\begin{aligned}
& m(g)=9.87028+4.96455^{*} V+0.41911^{*} V^{2} \\
& -0.06976^{*} V^{3}+0.00956^{*} V^{4}-3.84615^{*} 10^{-4} * V^{5} \\
& r^{2}=0.999 \text { And } \sigma=0.043 \\
& r^{2}: \text { Correlation coefficient } \\
& \sigma: \text { Residual sum of squares }
\end{aligned}
$$

\section{CONVERSION THE MASS IN}

\section{DISPLACEMENT}

The curve of Determination of the displacement X obtained by conversion the masses in displacement while using the characteristic for spring $K$ (with $K=2 \mathrm{~g} / \mathrm{mm}$ ).

Table -2: Sensor Electromagnetic of Displacement Calibration

\begin{tabular}{|l|l|l|l|l|l|l|}
\hline $\mathbf{d}(\mathbf{m m})$ & 0 & 0.5 & 1 & 1.5 & 2 & 2.5 \\
\hline $\mathbf{V ( m v )}$ & 9.85 & 15.25 & 21.05 & 27.25 & 34.05 & 41.25 \\
\hline
\end{tabular}

\begin{tabular}{|l|l|l|l|l|l|}
\hline $\mathbf{d}(\mathbf{m m})$ & 3 & 3.5 & 4 & 4.5 & 5 \\
\hline $\mathbf{V}(\mathbf{m v})$ & 49.15 & 57.65 & 67.15 & 77.75 & 88.75 \\
\hline
\end{tabular}

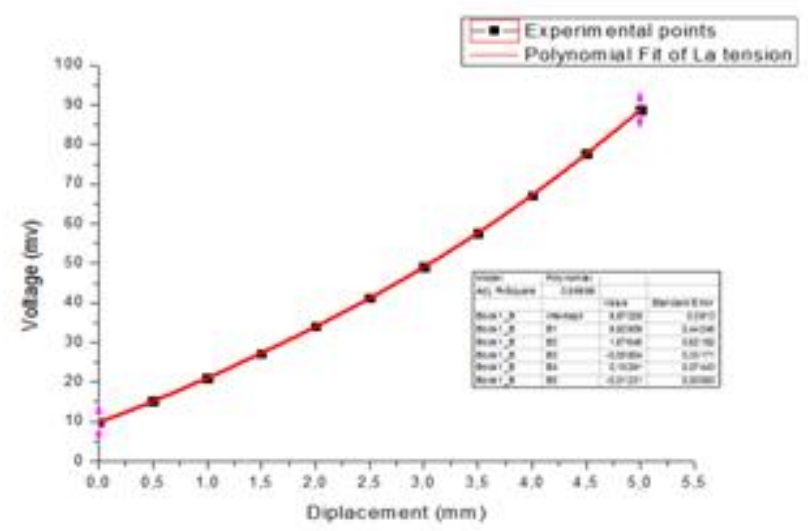

Chart -2: Sensor response from $0 \mathrm{~mm}$ to $5 \mathrm{~mm}: \mathrm{d}=\mathrm{f}(\mathrm{V})$

The polynomial adjustment of the mass as a function of the voltage corresponding to the experimental accuracy of our sensor is as follows:

$$
\begin{aligned}
& d(m m)=9.87028+9.92909 * V+1.67646^{*} V^{2} \\
& -0.55804^{*} V^{3}+0.15291^{*} V^{4}-0.012311^{*} V^{5}
\end{aligned}
$$


$r^{2}=1$ And $\sigma=0.24913$

$r^{2}$ : Correlation coefficient

$\sigma:$ Residual sum of squares

\section{CONCLUSIONS}

The electromagnetic sensor of force-displacement is characterized in that is characterized in that it comprises the diameter of the spools, the number of spires of every spool, and the section of the thread that can be modified. The choice of the constant $\mathrm{k}$ of the spring permits to fix the extended of measure and the range of use.

The proposed electromagnetic sensor of force-displacement, composed of a spring which allows the displacement in conversion of the forces, at which we have associated a magnetic circuit for converting the displacements into electrical voltages via a conditioning circuit, this voltage is displayed by a digital voltmeter precision $0.1 \mathrm{mV}$. The calibration of the electromagnetic balance, using precision masses of from $0 \mathrm{~g}$ to $10 \mathrm{~g}$, into a field of gravity given constant, allows us to make use of weighing with high accuracy.

The range of use of this scale is between $0 \mathrm{~g}$ and $10 \mathrm{~g}$, with an accuracy $\Delta \mathrm{m}=0.33 \mathrm{mg}$ and up to $0.1 \mathrm{mg}$. The measurements are reproducible and deformations of the spring are perfectly reversible within this range of measures.

In the best conditions of working, the precisions of these sensors become: $4 \mathrm{mg} \leq \Delta \mathrm{m} \leq 10 \mathrm{mg}$ and $2 \mu \mathrm{m} \leq \Delta \mathrm{x} \leq 5 \mu \mathrm{m}$.

Finally, some improvements could be brought to this sensor, to make the more effective and promising to numerous industrial applications.

\section{REFERENCES}

[1] Georges Asch, Les capteurs en instrumentation industrielle, Dunod,(ISBN 2100057774)

[2] P.Poulichet Etude des capteurs magnétiques (www.incertitudes.fr/robot/capteurs-

magnetique.pdf)

[3] Sensor One AE-801 Micro Force Sensor, http://sensorone.com/AE801 Home.

[4] T. Itoh, T. Suga, Self-excited force-sensing microcantilevers with piezoelectric thin films for dynamic scanning force microscopy, Sens. Actuators A: Phys.54(June(1-3))(1996)477-481.

[5] Beroulle, V.; Bertrand, Y.; Latorre, L.; Nouet, P. Monolithic Piezoresistive CMOS magnetic field sensors. Sens. Actuators A 2003, 103, 23-32

[6] Herrera-May, A.L.; García-Ramírez, P.J.; AguileraCortés, L.A.; Martínez-Castillo, J.; SaucedaCarvajal, A.; García-González, L.; Figueras-Costa, E. A resonant magnetic field microsensor with high quality factor at atmospheric pressure. J. Micromech. Microeng. 2009, 19, 015016

[7] [18] J. K. Spong, V. S. Speriosa, R. E. Fontana, Jr., M. M. Dovek, and T. L. Hylton, "Giant
Magnetoresistive Spin Valve Bridge Sensor," IEEE Trans. Magn., vol. 32, 366-371 (1996).

[8] J. Daughton, J. Brown, R. Beech, A. Pohm, and W. Kude, "Magnetic Field Sensors Using GMR Multilayer," IEEE Trans. Magn., vol. 30, 46084610,(1994).

[9] J.E. Lenz, G.F.Rouse, L.K. Strandjord, B.B.Pant, A.Metze, H.B.French, E.T.Benser, D.R.Krahn, "A Highly Sensitive Magnetoresistive Sensors", Solid State Sensors and Actuator Workshop, 1992.

[10] D.Cordier- Cours de physique, électromagnétisme, 1.Electrostatique et magnétostatique - Editions Dunod.22 juillet 2004.

[11] National Semiconductor, Application note 31: Op amp circuit collection, http://www.national.com/an/AN/AN-31.pdf, September, 2002. 